\title{
ESTRUTURA DO COMPONENTE ARBUSTIVO-ARBÓREO DA FLORESTA ATLÂNTICA DE ENCOSTA, PERUÍBE, SP ${ }^{1}$
}

\author{
Rosemary de Jesus Oliveira ${ }^{2}$ \\ Waldir Mantovani ${ }^{3}$ \\ Maria Margarida da Rocha Fiuza de Melo²
}

Recebido em 29/09/00. Aceito em 25/07/01.

\begin{abstract}
RESUMO - (Estrutura do componente arbustivo-arbóreo da floresta atlântica de encosta, Peruíbe, SP). Foi comparada a estrutura do componente arbustivo-arbóreo da floresta pluvial tropical atlântica de encosta, em diferentes classes de tamanho, e discutida a dinâmica de sua regeneração. Para a amostragem da vegetação foram utilizadas parcelas com dimensões que variaram de acordo com a classe de tamanho considerada: Classe I (indivíduos com altura $\leq 15,0 \mathrm{~cm})-250$ parcelas de $1 \mathrm{x} 1 \mathrm{~m}$, tomadas em cinco amostras de 50 unidades, com intervalo trimestral, no período entre julho/95 e julho/96; Classe II (altura $>15,0 \mathrm{~cm}$ e $\leq 1,30 \mathrm{~m}$ ) - dez parcelas de 2,5x $5 \mathrm{~m}$; Classe III (altura $>1,30 \mathrm{~m}$ e DAP $<5,0 \mathrm{~cm}$ ) - dez parcelas de $5 \times 10 \mathrm{~m}$ e Classe IV (DAP $\geq 5,0 \mathrm{~cm}$ ) - dez parcelas de 10x20m. Obteve-se maior diversidade para as classes intermediárias, devido à distribuição mais eqüitativa dos indivíduos entre as espécies, sendo também mais similares floristicamente. A maioria das espécies e dos indivíduos pertenciam às categorias sub-bosque e secundárias tardias-climácicas, em todas as classes de tamanho, sugerindo que a estrutura atual da floresta tem favorecido a regeneração destes grupos.
\end{abstract}

Palavras-chave - Floresta pluvial Atlântica, estrutura, classes de tamanho, regeneração.

ABSTRACT - (Structure of the tree and shrub component of the Atlantic rain forest, Peruíbe, SP). In this study the structure of the sub-montane Atlantic tropical rain forest tree and shrub component in different size classes was compared and their regeneration dynamics was discussed. The plants in each size class were sampled in plots of different size: Class I (individuals $\leq 15 \mathrm{~cm}$ tall) in $2501 \times 1 \mathrm{~m}$ plots taken in five main samples of 50 units, at three-months intervals, between July/95 and July/96; Class II (individuals $>15 \mathrm{~cm}$ and $\leq 1,3 \mathrm{~m}$ tall) in ten $2,5 \times 5 \mathrm{~m}$ plots; Class III (individuals $>1,3 \mathrm{~m}$ tall and $<5,0 \mathrm{~cm} \mathrm{DBH}$ ) in ten $5 \times 10 \mathrm{~m}$ plots and Class IV (individuals $\geq 5 \mathrm{~cm}$ $\mathrm{DBH}$ ) in ten $10 \times 20 \mathrm{~m}$ plots. The highest diversity was found in intermediate size classes was due to a more even distribution of individuals among species. These classes had also the highest values of quantitative and qualitative species similarity indices. The majority of the species and the individuals were secondary-climax and understory, suggesting that the present forest structure have favored the regeneration of these plant groups.

Key words - Atlantic rain forest, structure, size classes, regeneration.

\footnotetext{
${ }^{1}$ Parte da dissertação de Mestrado de R.J. Oliveira (Bolsista FAPESP, processo no 95/4951-0)

${ }^{2}$ Instituto de Botânica, Caixa Postal 4005, 01061-970 São Paulo, SP, Brasil

${ }^{3}$ Departamento de Ecologia Geral, Universidade de São Paulo, Caixa Postal 11461, 05408-400 São Paulo, SP, Brasil
} 


\section{Introdução}

Florestas Pluviais Tropicais naturais ou pouco alteradas são consideradas estruturalmente estáveis, mantendo uma relação aproximadamente logarítmica entre a diminuição do número e o aumento do tamanho das árvores, como conseqüência da dinâmica florestal, onde o espaço disponível limita o número de árvores que podem ser acomodadas em qualquer classe de tamanho. A contínua mortalidade permite que mais árvores cresçam e sejam recrutadas, garantindo a auto-manutenção da floresta (Swaine 1990).

Com a morte de árvores, a cobertura da floresta, mesmo nas primárias, é constantemente interrompida por clareiras que variam de tamanho e de freqüência, dependendo do tipo de morte, ou distúrbio, que pode ser a morte individual de árvore senescente, ou de um grupo de árvores. O tamanho da clareira formada vai determinar o tamanho do fragmento de regeneração, a composição e a distribuição das espécies na floresta. Por conta disso, a Floresta Pluvial Tropical pode ser definida como um mosaico irregular de estádios de desenvolvimento, chamados de fases estruturais de clareira, de construção e de maturidade, de acordo com a variação da composição florística e da estrutura (Whitmore 1989).

Outro fator importante é que o tamanho e a freqüência de clareiras variam de comunidades jovens a maduras, determinando a composição de espécies regenerando com sucesso sob cada circunstância. Baseado nos requerimentos para a germinação e o estabelecimento das plântulas, as espécies arbóreas têm sido agrupadas em guildas de regeneração, que podem ser, resumidamente, definidas como tolerantes à sombra e exigentes de luz (Denslow 1980; Whitmore 1996).

O estudo dos fenômenos que influem na substituição de uma árvore por outra, ocorrendo em pequenas escalas espaciais, podem constituir a base do entendimento da organização da comunidade arbórea que cresce em uma localidade (Martinez-Ramos 1991). Geralmente essas mudanças têm sido associadas à heterogeneidade ambiental criada pela dinâmica das clareiras (Denslow 1987).

Em florestas tropicais, o estudo da estrutura da vegetação tem se restringido, em grande parte, ao conjunto de árvores adultas e, mais recentemente, tem se voltado a outras classes de tamanho, principalmente às plântulas e indivíduos jovens, por representarem o potencial regenerativo da estrutura arbórea (Martínez-Ramos 1991). Estas fases do ciclo de vida, juntamente com a fase de semente, são consideradas como as de maior pressão demográfica, o que torna seu estudo fundamental para a interpretação da composição e da estrutura de florestas (Córdova-Casillas 1985; Whitmore 1996).

Para a Floresta Pluvial Atlântica a tendência tem sido a mesma, podendo ser citados vários estudos que caracterizaram a comunidade arbórea adulta (Silva \& Leitão-Filho 1982; Mantovani 1993; Melo \& Mantovani 1994, Melo et al. 1998, entre outros) e, mais recentemente, visando inferir sobre a modificação da estrutura ao longo do tempo, têm-se os estudos que incluem as plantas jovens (Tabarelli et al. 1993; Knobel 1995; Delamônica 1997).

No presente estudo foi comparada a estrutura do componente arbustivo-arbóreo de um trecho de Floresta Pluvial Atlântica secundária de encosta, em diferentes classes de tamanho dos indivíduos, e discutida a dinâmica de sua regeneração.

\section{Material e métodos}

Este estudo foi realizado na face voltada para o oceano do Morro do Fernando (25 $17^{\prime}$ S e $47^{\circ} 00^{\prime} \mathrm{W}$ ), localizado no Núcleo Arpoador, extremo nordeste da Estação Ecológica JuréiaItatins (EEJI), no litoral sul do estado de São Paulo. A estação situa-se entre as coordenadas $24^{\circ} 17^{\prime}-35^{\prime} \mathrm{S}$ e $47^{\circ} 00^{\prime}-30^{\prime} \mathrm{W}$ e tem área aproxi- 
mada de 80.000 ha. O Morro do Fernando, com altitude máxima de $250 \mathrm{~m}$.s.m., pertence ao agrupamento de maciços costeiros e ilhas continentais que vai desde o maciço de Peruíbe até a Ilha do Cardoso, com predomínio de rochas granitizadas, pertencentes ao complexo costeiro Atlântico, de idade Pré-Cambriana.

Estes maciços possuem gênese complexa e, à despeito da declividade de suas encostas, são cobertos por solos tênues, com predomínio de Litossolos e colúvios (Ab’Saber 1985).

O clima regional é do tipo Af, tropical chuvoso de floresta, segundo Koeppen (1948). O período de maior precipitação coincide com o de maior temperatura, de dezembro a março. A média anual de precipitação, no período de 1982 a 1991, para o posto mais próximo da área de estudo (F4-027-Peruíbe), foi de $2000 \mathrm{~mm}$, com dois meses apresentando média mensal inferior a $100 \mathrm{~mm}$ (julho e agosto), sem caracterizar um período de seca (dados fornecidos pelo Departamento de Águas e Energia Elétrica - DAEE). A temperatura média anual para a região de Iguape, no período de 1977 a 1986 , foi de $22^{\circ} \mathrm{C}$, sendo que a média do mês mais quente (fevereiro) foi de $26,2^{\circ} \mathrm{C}$ e a do mês mais frio (julho), de $19^{\circ} \mathrm{C}$ e a umidade relativa do ar média anual foi superior a $80 \%$ (Nascimento \& Pereira 1988).

Os solos que recobrem as serras da EEJI são associações de Podzólico Vermelho-Amarelo distrófico com Podzólico Vermelho distrófico, Cambissolo distrófico associado com
Cambissolo distrófico álico, com argilas de baixa atividade, de textura muito argilosa e fase pedregosa com textura média e solo gleizado álico, todos com horizonte A moderado (Lepsch et al. 1988).

A vegetação que recobre o Morro do Fernando é a Floresta Pluvial Atlântica de encosta, ou Floresta Ombrófila Densa Submontana, segundo classificação de Veloso et al. (1991). É um trecho de floresta secundária, com aproximadamente 50 anos, com o componente arbóreo bem desenvolvido, embora ocorra, devido ao grau de inclinação do terreno, penetração de luz no seu interior, permitindo o adensamento do sub-bosque, que em alguns locais é dominado por bambus e bambusóides como Merostachys sp. e Olyra micrantha H.B.K. (Gramineae).

Para a amostragem da vegetação, definiuse como arbustivo-arbóreas as plantas com a base do caule lenhosa e auto sustentação, incluindo-se os arbustos, as árvores, as palmeiras e os fetos arborescentes. Os indivíduos foram amostrados em quatro classes de tamanho, através do método de parcelas (Mueller-Dombois \& Ellenberg 1974), cujas áreas variaram de acordo com a classe considerada e o critério de inclusão em cada classe foi estabelecido com base na altura total da planta e no diâmetro do tronco a 1,30m de altura do solo (DAP) (Tab. 1). A Classe I, por representar a fase de dinâmica mais rápida, foi amostrada sazonalmente através de cinco amostras tomadas em intervalos trimes-

Tabela 1. Critério de inclusão dos indivíduos, número e tamanho das parcelas utilizadas para amostragem das classes de tamanho do componente arbustivo-arbóreo da Floresta Atlântica de encosta, no Morro do Fernando (EEJI, Peruíbe, SP).

\begin{tabular}{llccc}
\hline $\begin{array}{l}\text { Classe de } \\
\text { tamanho }\end{array}$ & $\begin{array}{l}\text { Critério de inclusão } \\
\text { dos indivíduos }\end{array}$ & $\begin{array}{c}\text { Número de } \\
\text { parcelas }\end{array}$ & $\begin{array}{c}\text { Tamanho das } \\
\text { parcelas }\end{array}$ & $\begin{array}{c}\text { Área } \\
\text { amostrada }\end{array}$ \\
\hline I* & Altura $\leq 15,0 \mathrm{~cm}$ & 250 & $1 \times 1 \mathrm{~m}$ & $250 \mathrm{~m}^{2}$ \\
II & Altura $\leq 1,30 \mathrm{~m} \mathrm{e}>15,0 \mathrm{~cm}$ & 10 & $2,5 \times 5 \mathrm{~m}$ & $125 \mathrm{~m}^{2}$ \\
III & DAP $<5,0 \mathrm{~cm}$ e altura $>1,30 \mathrm{~m}$ & 10 & $5 \times 10 \mathrm{~m}$ & $500 \mathrm{~m}^{2}$ \\
IV & DAP $\geq 5,0 \mathrm{~cm}$ & 10 & $10 \times 20 \mathrm{~m}$ & $2.000 \mathrm{~m}^{2}$ \\
\hline
\end{tabular}

*Classe amostrada sazonalmente através de 5 amostras de 50 unidades. 
trais, durante o período de um ano, sendo cada amostra composta por 50 parcelas de $1 \mathrm{~m}^{2}$.

Para as Classes II, III e IV foram tomadas amostras únicas com dez parcelas cada. As parcelas utilizadas para a amostragem da Classe IV $(10 \times 20 \mathrm{~m})$ foram instaladas de maneira disjunta e assistemática, aproximadamente à cota altitudinal de 50m.s.m, evitando-se trechos com adensamentos de bambus. As parcelas menores foram dispostas internamente a estas, de maneira que as parcelas utilizadas para a amostragem das Classes III $(5 \times 10 \mathrm{~m})$ e II $(2,5 \times 5 \mathrm{~m})$ tinham em comum um de seus vértices e as utilizadas para a amostragem da Classe I $(1 \mathrm{x} 1 \mathrm{~m})$ foram distribuídas em locais estabelecidos através de sorteio, sem reposição, para evitar a sobreposição nas sucessivas coletas, sendo retiradas cinco unidades de cada parcela de $10 \times 20 \mathrm{~m}$ a cada coleta.

Buscou-se com esta divisão amostrar um número próximo de indivíduos em cada classe de tamanho, exceto para a Classe I que foi amostrada sazonalmente. Esta metodologia, além da descrição da estrutura, permite inferir características dinâmicas das populações constituintes (Mantovani et al. 1990).

Iniciou-se a amostragem pela Classe I, onde todos os indivíduos foram coletados no momento da amostragem, com exceção dos de Euterpe edulis Mart. que, por serem de fácil reconhecimento, foram contados no campo. Os indivíduos das demais classes tiveram tomadas as medidas de altura total e de diâmetro do caule na altura do solo (DAS), para as Classes II e III, e a $1,30 \mathrm{~m}$ da altura do solo (DAP), para a Classe IV. No caso de indivíduos ramificados, foi considerado o diâmetro do caule maior para a inclusão em uma das classes de tamanho e todos os demais foram medidos e acrescentados no cálculo da área basal do indivíduo. Foram tomadas amostras de material botânico dos indivíduos em todas as classes de tamanho, que encontram-se depositadas no Herbário do Instituto de Botânica (SP). As espécies foram dispostas em famí- lias de acordo com o sistema de Cronquist (1988).

Para a discussão da dinâmica do componente, as espécies foram separadas em categorias sucessionais, baseando-se em informações de diversos autores: Klein (1980), Mantovani (1993), Leitão-Filho (1993), Rossi (1994), Tabarelli (1994), Knobel (1995), Delamônica (1997) e Flora Ilustrada Catarinense (Reitz 1965-1990). Em todos os casos, a separação das espécies baseou-se nos critérios propostos por Budowski (1970), sendo consideradas as categorias: pioneiras (PI), secundárias iniciais (SI) e secundárias tardias - climácicas (ST). As espécies de sub-bosque (SB) foram consideradas como um grupo à parte, compreendendo as espécies que completam todo seu ciclo de vida no interior da floresta, devido à falta de informações sobre seus requerimentos para germinação e estabelecimento, constituindo mais um grupo funcional do que sucessional (Tabarelli et al. 1993). As espécies foram ainda separadas quanto à síndrome de dispersão dos propágulos em anemocóricas, autocóricas e zoocóricas, de acordo com os critérios propostos por van der Pijl (1982).

O tratamento dos dados foi realizado através do Programa FITOPAC (Shepherd 1996), sendo calculados os parâmetros: densidade, freqüência, dominância e índice do valor de importância (VI), descritos em Mueller-Dombois \& Ellenberg (1974), e o índice de diversidade específica de Shannon-Wiener (H') e o de eqüabilidade (J), descritos em Magurran (1988).

Para verificar a variação na riqueza e na abundância entre as classes de tamanho foram calculados os índices de similaridade de Sørensen, de Bray-Curtis e de Morisita-Horn (Magurran 1988; Krebs 1989). Os valores calculados pelos três índices variam de 0 a 1 e, no caso do índice de Bray \& Curtis, por ser uma medida de distância, a similaridade foi obtida pela diferença entre a unidade e o valor calculado do índice. As classes foram consideradas similares quando o valor do índice foi superior 
a 0,5 e mais similares quanto mais o valor se aproximasse de 1 .

A variação da distribuição espacial horizontal dos indivíduos e das espécies, nas diferentes classes de tamanho, foi analisada através do cálculo do índice de dispersão (ID) (Variância observada/média observada) e do respectivo Quiquadrado da distribuição de Poisson (ID (n - 1), onde $\mathrm{n}=$ número de parcelas (Krebs 1989). O índice de dispersão foi ainda calculado para as dez espécies mais abundantes do levantamento como um todo e a relação espacial da abundância dessas espécies, nas diferentes classes de tamanho, foi verificada através da ordenação da abundância nas parcelas pelo método da Análise de Correspondência (Correspondence Analysis - CA) (Greig-Smith 1983).

\section{Resultados}

Foram amostradas no total 125 espécies de 90 gêneros, pertencentes a 45 famílias de angiospermas e uma de pteridófita. Destas, $54,4 \%$ estavam representadas na Classe I; 47,2\% na Classe II; 48,8\% na Classe III e 50,4\% na Classe IV. Quanto à classificação em categorias sucessionais, a maior proporção das espécies era de sub-bosque $(48,0 \%)$ e secundárias tardias-climácicas $(29,6 \%)$, as secundárias iniciais somaram $11,2 \%$ e as pioneiras $4,8 \%$. A síndrome de dispersão predominante foi a zoocoria, apontada em $85 \%$ das espécies, enquanto que a anemocoria representou $9 \%$ e a autocoria 6\% (Tab. 2).

As famílias com maiores números de espécies foram Myrtaceae (com 26 espécies), Rubiaceae (11) e Lauraceae (7), representadas por $35,2 \%$ do total de espécies amostradas. Myrtaceae esteve bem representada em todas as classes de tamanho e correspondeu juntamente com Rubiaceae a $46 \%$ das espécies de subbosque. Lauraceae, assim como Moraceae e Sapotaceae, foi mais rica na Classe IV, devido à ocorrência de espécies exclusivas desta classe, como Aniba sp., Nectandra grandiflora e
Ocotea odorifera, amostradas por uma única árvore.

Uma síntese dos parâmetros obtidos em cada classe de tamanho encontra-se na tabela 3. Ocorreu uma diminuição exponencial da densidade média com o aumento das classes de tamanho dos indivíduos, enquanto que para a área basal verificou-se o oposto, numa proporção duas vezes maior (Tab. 3 ).

As espécies amostradas por um único indivíduo corresponderam a uma proporção próxima a $40 \%$, em cada classe, tendendo a aumentar nas classes de tamanhos maiores. Estas espécies corresponderam, em grande parte, às amostradas exclusivamente em cada classe.

A estrutura da distribuição dos indivíduos por espécies, sintetizada pelos valores de diversidade (H') e de eqüabilidade (J), revelou menor diversidade na Classe I, onde ocorreu maior número de espécies, porém poucas predominaram em número de indivíduos, como mostra o baixo valor de eqüabilidade. Valores mais altos de diversidade e de eqüabilidade foram obtidos para as classes intermediárias, devido à distribuição mais uniforme dos indivíduos entre as espécies.

Os parâmetros fitossociológicos calculados para as espécies, em cada classe de tamanho, estão apresentados na tabela 4 . Na Classe I, foram amostrados 737 indivíduos de 68 espécies. As mais importantes são três espécies de dossel, Euterpe edulis, Guapira opposita e Eriotheca pentaphylla, que somam $43,6 \%$ do valor de importância total (VI). E. edulis foi considerada como espécie de dossel neste estudo, apesar de ser apontada na maioria dos trabalhos efetuados na Floresta Pluvial Atlântica como espécie de sub-bosque.

As espécies amostradas por um único indivíduo (40,0\% do total), contribuem com apenas $5 \%$ do VI total e $20,6 \%$ das espécies foram amostradas somente nesta classe. Entre estas, destaca-se Eupatorium sp. como uma das mais abundantes, porém com freqüência baixa. $\mathrm{Na}$ Classe II foram amostrados 232 indivíduos de 
Tabela 3. Síntese dos parâmetros estruturais obtidos para as quatro classes de tamanho do componente arbustivo-arbóreo da Floresta Atlântica de encosta, no Morro do Fernando (EEJI, Peruíbe, SP).

\begin{tabular}{|c|c|c|c|c|}
\hline \multirow[t]{2}{*}{ Parâmetros } & \multicolumn{4}{|c|}{ Classes de tamanho } \\
\hline & I & II & III & IV \\
\hline Área amostrada $\left(\mathrm{m}^{2}\right)$ & 250 & 125 & 500 & 2.000 \\
\hline $\mathrm{N}^{\circ}$ de indivíduos amostrados & 737 & 232 & 281 & 284 \\
\hline Densidade ( $\mathrm{N}^{\circ}$ de indivíduos.ha $\left.{ }^{-1}\right)$ & 26.200 & 18.560 & 5.640 & 1.420 \\
\hline Área basal $\left(\mathrm{m}^{2} \cdot \mathrm{ha}^{-1}\right)$ & - & 1,11 & 5,92 & 40,38 \\
\hline Altura média (m) & - & 0,47 & 2,50 & 9,56 \\
\hline Diâmetro médio $(\mathrm{cm})$ & - & 0,67 & 2,80 & 15,12 \\
\hline $\mathrm{N}^{\circ}$ de espécies amostradas & 68 & 59 & 62 & 63 \\
\hline № de gêneros amostrados & 54 & 45 & 52 & 52 \\
\hline $\mathrm{N}^{\circ}$ de famílias amostradas & 31 & 30 & 33 & 29 \\
\hline № de espécies amostradas por 1 indivíduo (\%) & $27(39,7)$ & $25(42,4)$ & $28(45,2)$ & $28(44,4)$ \\
\hline \% espécies exclusivas a cada classe & 20,6 & 13,5 & 21,3 & 31,7 \\
\hline$\%$ das exclusivas amostradas por 1 indivíduo & 10,3 & 13,5 & 18 & 20,6 \\
\hline Diversidade $-\mathrm{H}^{\prime}\left(\right.$ nats.ind $\left.^{-1}\right)$ & 2,880 & 3,607 & 3,550 & 3,380 \\
\hline Equabilidade (J) & 0,682 & 0,885 & 0,860 & 0,816 \\
\hline
\end{tabular}

59 espécies. As mais importantes são as mesmas da Classe I, porém representando uma proporção maior do VI total $(29,9 \%)$. A proporção das espécies amostradas por um único indivíduo nesta classe é $42,4 \%$ que somam $13,6 \%$ do VI total. As espécies exclusivas representam $13,5 \%$, sendo todas amostradas por um único indivíduo. Nesta classe, espécies arbustivas, como Psychotria birotula, P. kleinii e Pavonia schiedeana, e arbóreas, como Garcinia gardneriana e Brosimum guianense, com indivíduos de rebrotas, apresentam altos VIs, devido à dominância relativa. Na Classe III, o total de indivíduos amostrados foi 281 e o de espécies foi 62. Eugenia bocainensis, Guapira opposita, Euterpe edulis, Garcinia gardneriana, Marlierea reitzii, Tabebuia obtusifolia e Eriotheca pentaphylla são as mais importantes, contribuindo com $44,3 \%$ do VI total. $45,2 \%$ das espécies foram amostradas por um único indivíluo que somam $11,6 \%$ do VI total e $21,3 \%$ sã espécies xclusivas. Esta classe representa o Imite máxi no de tamanho para muitas espéciss típicas de sub-bosque, como Psychotria kl inii, Pavor ia schiedeana, Piper spp., Rudgea villiflora, Cestrum schlechtendalli, Geonoma elegans e Bactris setosa, entre outras. Na Classe IV, foram amostrados 284 indivíduos de 63 espécies. Eriotheca pentaphylla, Tabebuia obtusifolia, Euterpe edulis, Ecclinusa ramiflora, Guapira opposita e Chrysophyllum flexuosum são as mais importantes e somam $43,5 \%$ do VI total. A proporção de espécies exclusivas e daquelas amostradas por um único indivíduo é de 31,7 e $44,4 \%$ do total, respectivamente, sendo, a maioria, espécies de dossel e emergentes. As espécies amostradas uma única vez contribuem com $11,7 \%$ do VI total. A posição hierárquica de E. pentaphylla e $T$. obtusifolia, deve-se aos maiores valores de dominância em relação a $E$. edulis, que é a mais abundante. Outras espécies com altos valores de dominância são Guapira opposita, Pterocarpus rohrii, Eugenia pruinosa e Balizia pedicellaris.

Houve maior similaridade entre as classes de tamanho intermediárias (II e III), pelos três índices considerados (Tab. 5). O maior valor foi conferido pelo índice quantitativo de MorisitaHorn $(0,78)$, que apontou maior similaridade entre as espécies mais abundantes, comuns a 
estas classes, como Garcinia gardneriana, Guapira opposita, Eugenia bocainensis, E. peruibensis, E. cerasifolia e Euterpe edulis. As Classes I e II, com maior número de espécies em comum (39), foram consideradas igualmente similares pelo índices de Sørensen e de MorisitaHorn $(0,61$ e 0,60$)$, porém muito dissimilares pelo de Bray-Curtis $(0,29)$ que detectou o maior número de espécies e a maior abundância de algumas espécies na Classe I. Eupatorium sp., Myrsine umbellata e Myrsine sp. estiveram entre as dez mais abundantes da Classe I, mas não foram amostradas na Classe II, sendo espécies pioneiras e secundárias iniciais.

As duas categorias sucessionais mais abundantes foram secundária tardiaclimácica, com 57,4\% dos indivíduos, e de sub-bosque, com 33,2\% (Fig. 1). Estes grupos apresentaram maior riqueza e abundância em todas as classes de tamanho. As espécies de sub-bosque corresponderam a cerca de $50 \%$ do total, nas Classes I, II e III e a $31,7 \%$, na Classe IV, apresentando maior número de indivíduos nas classes intermediárias. Uma tendência contrária foi verificada para o grupo de secundárias tardias-climácicas, com maior proporção de espécies na Classe IV $(49,2 \%)$ e de indivíduos nas Classes I e IV. As espécies secundárias iniciais corresponderam a $11,2 \%$ do total, representadas por $3,5 \%$ dos indivíduos. Estiveram em maior proporção na

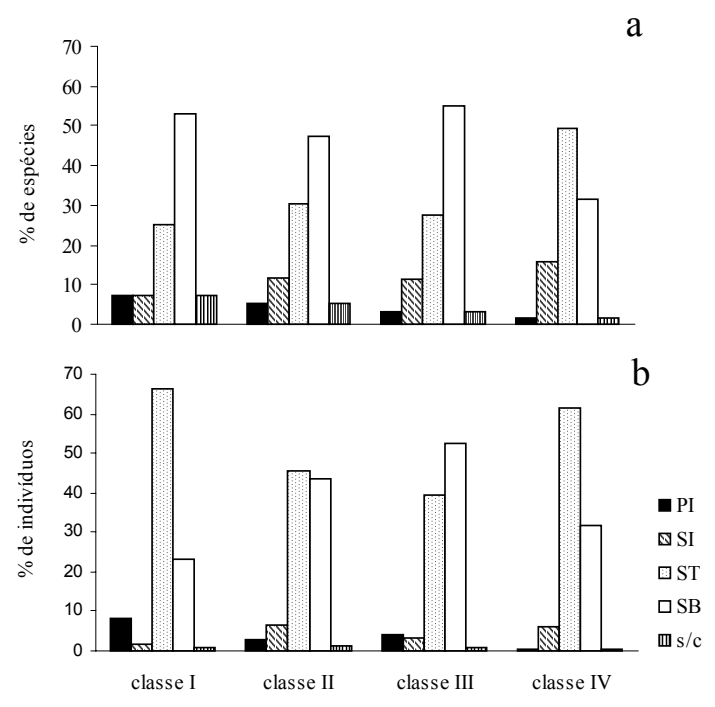

Figura 1. Porcentagem de espécies (a) e de indivíduos (b) por categorias sucessionais, nas Classes I, II, III e IV do componente arbustivo-arbóreo da Floresta Atlântica de encosta, no Morro do Fernando (EEJI, Peruíbe, SP). PI: pioneiras, SI: secundárias iniciais, ST: secundárias tardias, SB: sub-bosque e s/c: sem classificação.

Classe IV (15,9\% do total de espécies) e em menor na Classe I (7,3\%), apresentando maior número de indivíduos nas Classes II e IV. As pioneiras representaram a menor proporção, com $4,8 \%$ do total de espécies, porém foram mais abundantes que as secundárias iniciais, com $5,2 \%$ do total de indivíduos. Ao contrário das espécies secundárias iniciais, estiveram em maior proporção na Classe I, com 7,3\% das es-

Tabela 5. Similaridade entre as classes de tamanho do componente arbustivo-arbóreo da Floresta Atlântica de encosta, no Morro do Fernando (EEJI, Peruíbe, SP), pelos índices qualitativo de Sørensen e quantitativos de Bray-Curtis e MorisitaHorn.

\begin{tabular}{lcccc}
\hline $\begin{array}{l}\text { Classes } \\
\text { comparadas }\end{array}$ & $\begin{array}{c}\text { № de espécies } \\
\text { em comum }\end{array}$ & Sørensen & Bray-Curtis & Morisita-Hora \\
\hline I - II & 39 & 0,61 & 0,29 & 0,60 \\
I - III & 36 & 0,57 & 0,24 & 0,41 \\
I - IV & 29 & 0,47 & 0,32 & 0,68 \\
II - III & 37 & 0,64 & 0,59 & 0,78 \\
II - IV & 26 & 0,44 & 0,48 & 0,72 \\
III - IV & 28 & 0,46 & 0,42 & 0,59 \\
\hline
\end{tabular}




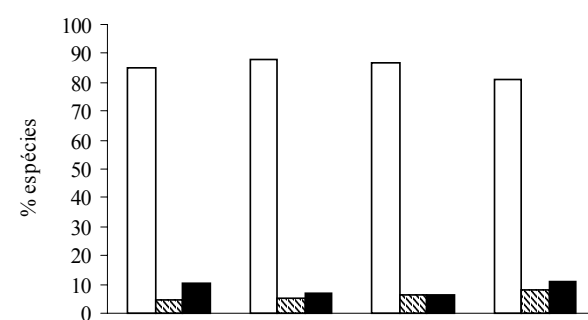

a

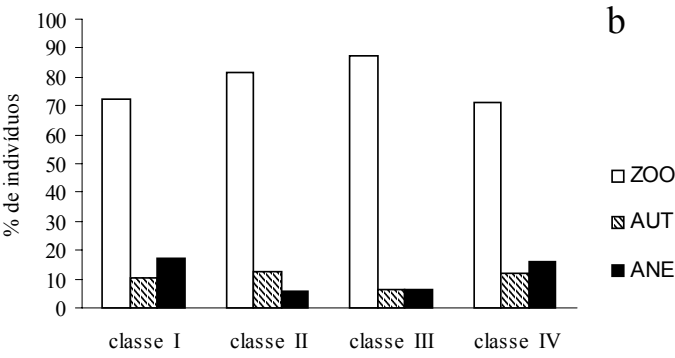

Figura 2. Porcentagem de espécies (a) e de indivíduos (b) classificados quanto à síndrome de dispersão dos propágulos, nas Classes I, II, III e IV do componente arbustivo-arbóreo da Floresta Atlântica de encosta, no Morro do Fernando (EEJI, Peruíbe, SP). ZOO: zoocoria, AUT: autocoria, ANE: anemocoria.

pécies e $8,3 \%$ dos indivíduos e, conforme aumenta a classe de tamanho, diminuem para $1,59 \%$ e $0,35 \%$ do total de espécies e de indivíduos, respectivamente, na Classe IV. Este grupo e o das secundária iniciais compreenderam grande parte das espécies exclusivas a cada classe. A zoocoria foi a síndrome de dispersão predominante em todas as classes de tamanho, presente em $85 \%$ das espécies e $77 \%$ dos indivíduos (Fig. 2). O número de espécies zoocóricas foi ligeiramente maior nas Classes II e III, representadas também por número maior de indivíduos nestas classes, associadas, principalmente, às espécies de sub-bosque.

A anemocoria esteve representada em 9\% do total de espécies e em $13 \%$ do total de indivíduos. Apresentou tendência oposta à zoocoria, estando presente em maior número de espécies e de indivíduos nas classes extremas (I e IV), associada, principalmente, às espécies pioneiras. A autocoria esteve presente em $6 \%$ das espécies, distribuídas igualmente entre as classes

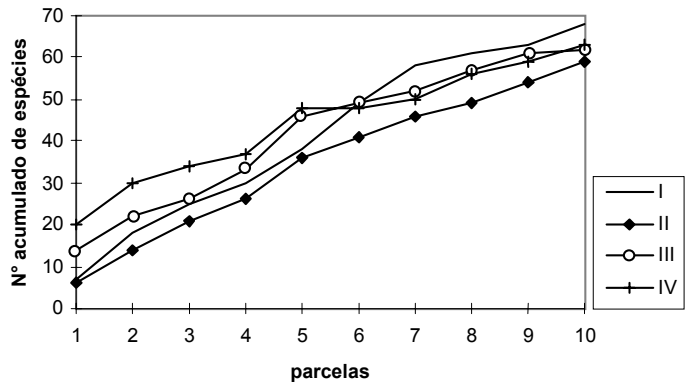

Figura 3. Curvas do número acumulado de espécies por parcela, em seqüencia original, utilizadas para a amostragem das Classes I, II, III e IV do componente arbustivo-arbóreo da Floresta Atlântica de encosta, no Morro do Fernando (EEJI, Peruibe, SP). Para a Classe I, a unidade representa a soma de 25 parcelas de $1 \mathrm{~m}^{2}$.

de tamanho, porém com menor número de indivíduos na Classe III. No total, correspondeu a $10 \%$ dos indivíduos.

A distribuição dos indivíduos foi considerada agregada nas Classes I, II e III e aleatória na Classe IV. Para o número de espécies, a distribuição foi considerada agregada somente na Classe I e aleatória nas demais (Tab. 6).

A heterogeneidade da distribuição pode ser constatada também pela análise do acréscimo de novas espécies por unidade de área amostrada, apresentado na figura 3. Nesse gráfico, observa-se maior alteração da composição para a Classe I, no segmento da curva entre as parcelas cinco e sete, e aumento da homogeneidade conforme aumenta a classe de tamanho.

Analisando o padrão de distribuição das dez espécies mais abundantes, no levantamento como um todo (Tab. 7), verifica-se que aquelas classificadas como secundárias tardiasclimácicas ou de sub-bosque, como Euterpe edulis, Guapira opposita, Eriotheca pentaphylla, Eugenia peruibensis e Balizia pedicellaris, apresentaram uma distribuição agregada dos indivíduos na Classe I (fase de plântulas), porém tendendo ao aleatório, conforme aumenta a classe de tamanho. Para Tabebuia obtusifolia verifica-se o oposto, sendo a distribuição aleatória na Classe I e agrega- 
Tabela 7. Padrão de distribuição espacial das 10 espécies mais abundantes amostradas nas classes de tamanhos I, II, III e IV do componente arbustivo-arbóreo da Floresta Atlântica de encosta, no Morro do Fernando (EEJ, Peruíbe, SP). Cód: código estabelecido para a ordenação das espécies (Fig. 6), ID: variância/média, $X^{2}$ : Qui-quadrado da distribuição de POISSON.

\begin{tabular}{|c|c|c|c|c|c|c|c|}
\hline Espécie & Cód & Classe & Média & Var & ID & $X^{2}$ & Padrão* \\
\hline Euterpe edulis & $1 \mathrm{~A}$ & I & 18,1 & 844,77 & 46,67 & 420,05 & Agregado \\
\hline Euterpe edulis & $1 \mathrm{~B}$ & II & 1,7 & 3,12 & 1,84 & 16,53 & Aleatório \\
\hline Euterpe edulis & $1 \mathrm{C}$ & III & 1,4 & 1,38 & 0,98 & 8,86 & Aleatório \\
\hline Euterpe edulis & $1 \mathrm{D}$ & IV & 3,8 & 16,40 & 4,32 & 38,84 & Agregado \\
\hline Guapira opposita & $2 \mathrm{~A}$ & I & 13 & 67,56 & 5,20 & 46,77 & Agregado \\
\hline Guapira opposita & $2 \mathrm{~B}$ & II & 1,9 & 5,21 & 2,74 & 24,68 & Agregado \\
\hline Guapira opposita & $2 \mathrm{C}$ & III & 2,3 & 7,12 & 3,10 & 27,87 & Agregado \\
\hline Guapira opposita & $2 \mathrm{D}$ & IV & 1,4 & 1,82 & 1,30 & 11,71 & Aleatório \\
\hline Eriotheca pentaphylla & $3 \mathrm{~A}$ & I & 7,4 & 112,04 & 15,14 & 136,27 & Agregado \\
\hline Eriotheca pentaphylla & $3 \mathrm{~B}$ & II & 1,9 & 11,21 & 5,90 & 53,11 & Agregado \\
\hline Eriotheca pentaphylla & $3 \mathrm{C}$ & III & 1,1 & 0,99 & 0,90 & 8,09 & Aleatório \\
\hline Eriotheca pentaphylla & $3 \mathrm{D}$ & IV & 2,9 & 5,66 & 1,95 & 17,55 & Aleatório \\
\hline Tabebuia obtusifolia & $4 \mathrm{~A}$ & I & 3,1 & 3,88 & 1,25 & 11,26 & Aleatório \\
\hline Tabebuia obtusifolia & $4 \mathrm{~B}$ & II & 0,4 & 0,93 & 2,33 & 21,00 & Agregado \\
\hline Tabebuia obtusifolia & $4 \mathrm{C}$ & III & 1,4 & 7,38 & 5,27 & 47,43 & Agregado \\
\hline Tabebuia obtusifolia & $4 \mathrm{D}$ & IV & 3 & 9,78 & 3,26 & 29,33 & Agregado \\
\hline Eugenia bocainensis & $5 \mathrm{~A}$ & I & 0,3 & 0,23 & 0,78 & 7,00 & Aleatório \\
\hline Eugenia bocainensis & $5 \mathrm{~B}$ & II & 1,6 & 1,82 & 1,14 & 10,25 & Aleatório \\
\hline Eugenia bocainensis & $5 \mathrm{C}$ & III & 2,5 & 3,83 & 1,53 & 13,80 & Aleatório \\
\hline Eugenia bocainensis & $5 \mathrm{D}$ & IV & 0,7 & 0,68 & 0,97 & 8,71 & Aleatório \\
\hline Eugenia peruibensis & $6 \mathrm{~A}$ & I & 0,5 & 1,17 & 2,33 & 21,00 & Agregado \\
\hline Eugenia peruibensis & $6 \mathrm{~B}$ & II & 0,8 & 1,51 & 1,89 & 17,00 & Aleatório \\
\hline Eugenia peruibensis & $6 \mathrm{C}$ & III & 1,2 & 1,73 & 1,44 & 13,00 & Aleatório \\
\hline Eugenia peruibensis & $6 \mathrm{D}$ & IV & 1,6 & 2,71 & 1,69 & 15,25 & Aleatório \\
\hline Balizia pedicellaris & $7 \mathrm{~A}$ & I & 3,1 & 44,10 & 14,23 & 128,03 & Agregado \\
\hline Balizia pedicellaris & $7 \mathrm{~B}$ & II & 0,5 & 2,50 & 5,00 & 45,00 & Agregado \\
\hline Balizia pedicellaris & $7 \mathrm{C}$ & III & 0,1 & 0,10 & 1,00 & 9,00 & Aleatório \\
\hline Balizia pedicellaris & $7 \mathrm{D}$ & IV & 0,2 & 0,18 & 0,89 & 8,00 & Aleatório \\
\hline Myrsine umbellata & $8 \mathrm{~A}$ & I & 3,2 & 5,73 & 1,79 & 16,13 & Aleatório \\
\hline Myrsine umbellata & $8 \mathrm{D}$ & IV & 0,2 & 0,18 & 0,89 & 8,00 & Aleatório \\
\hline Ecclinusa ramiflora & $9 \mathrm{~A}$ & I & 0,1 & 0,10 & 1,00 & 9,00 & Aleatório \\
\hline Ecclinusa ramiflora & $9 \mathrm{~B}$ & II & 0,9 & 2,32 & 2,58 & 23,22 & Agregado \\
\hline Ecclinusa ramiflora & $9 \mathrm{C}$ & III & 0,4 & 0,49 & 1,22 & 11,00 & Aleatório \\
\hline Ecclinusa ramiflora & $9 \mathrm{D}$ & IV & 1,8 & 3,51 & 1,95 & 17,56 & Aleatório \\
\hline Eupatorium sp. & $10 \mathrm{~A}$ & I & 5,5 & 83,39 & 15,16 & 136,45 & Agregado \\
\hline
\end{tabular}

*O padrão foi considerado aleatório para valores de $X^{2}$ entre 2,7 e 19,0, agregado se maior que 19,0 e uniforme se menor que 2,7 , para $\mathrm{p}=0,05$ e $\mathrm{gl}=9$. 
da nas demais classes. Essa espécie, considerada como secundária tardia neste estudo, tem sido classificada como secundária inicial por alguns dos autores consultados.

A distribuição aleatória na Classe I é verificada ainda para Myrsine umbellata, classificada também como secundária inicial, e para aquelas amostradas por um número pequeno de indivíduos nesta classe, como Eugenia bocainensis e Ecclinusa ramiflora. Para Eupatorium sp., espécie pioneira amostrada somente na Classe I, a distribuição foi agrupada.

Pela relação espacial da abundância dessas espécies nas diferentes classes de tamanho, através da Análise de Correspondência (CA), cujos dois primeiros eixos da ordenação responderam por $55,7 \%$ da variação existente entre os pontos (Fig. 4), verifica-se que há formação de dois grupos: um contendo as espécies com maior correlação com as parcelas cinco, seis e sete como Euterpe edulis, nas Classes I, II e IV, Eugenia peruibensis nas Classes I e II, E. bocainensis na Classes I e IV, Balizia pedicellaris em todas as classes e Eupatorium sp. na Classe I, representadas pelos valores negativos dos escores no Eixo 1, e outro, contendo o restante das espécies, com maior correlação com as demais parcelas.

Com a confecção dos diagramas de perfil foi possível ilustrar a variação fisionômica entre trechos da floresta estudada (Fig. 5a e b).

O diagrama (a) ilustra a parcela com maior número de indivíduos da Classe IV, parcela número oito. Neste diagrama destaca-se a presença de Pera glabrata, representada pelos indivíduos mais altos. Esta espécie, classificada como secundária inicial (SI), não foi amostrada em classes de tamanhos menores nesta parcela que, no geral, apresentou baixa densidade nas Classes I e II. Por outro lado, o diagrama (b), da

Tabela 6. Padrão de distribuição espacial do número de indivíduos e de espécies, em quatro classes de tamanho do componente arbustivo-arbóreo (I, II, III e IV) da Floresta Atlântica de encosta, no Morro do Fernando (EEJI, Peruíbe, SP). ID: variância/média, $X^{2}$ : Qui-quadrado da distribuição de POISSON (ID(n - 1), $\mathrm{n}=$ número de parcelas, $\mathrm{d}=\sqrt{2} X^{2}-$ $\sqrt{2}(\mathrm{n}-1)$-1 (aproximação normal do valor do $X^{2}$ calculado, para $\mathrm{n}>30$ ).

\begin{tabular}{lcccc}
\hline Indivíduos & Classe I & Classe II & Classe III & Classe IV \\
\hline $\mathrm{n}$ & 250 & 10 & 10 & 10 \\
Média & 2,9 & 23,2 & 28,2 & 28,4 \\
Variância & 15,90 & 134,56 & 92,10 & 39,10 \\
$\mathrm{ID}$ & 5,41 & 5,80 & 3,27 & 1,38 \\
$X^{2}$ & $1347,1\left(\mathrm{~d}=29,6^{*}\right)$ & $52,20^{*}$ & $29,39^{*}$ & 12,42 \\
\hline Espécies & & & & \\
\hline $\mathrm{n}$ & & & & \\
Média & 1,6 & 10 & 10 & 10 \\
Variância & 2,20 & 13,1 & 15,9 & 15,9 \\
ID & 1,37 & 1,75 & 1,60 & 8,76 \\
$X^{2}$ & $341,13\left(\mathrm{~d}=3,8^{*}\right)$ & 15,80 & 14,37 & 0,55 \\
& & & & 4,96 \\
\hline
\end{tabular}

*Distribuição agregada $(\mathrm{p}=0,05)$. Para as classes II, III e IV, com gl=9, a distribuição foi considerada aleatória quando os valores do $X^{2}$ observado ficou entre os valores críticos 2,7 e 19,0 e agregada, se maior que 19,0. Para a Classe I, gl= 249, a distribuição foi considerada aleatória para valores de d entre 1,96 e -1,96 e agregada para valores acima de 1,96 (Krebs, 1989). 
mesma figura, ilustra a parcela onde a densidade de indivíduos adultos foi comparativamente menor e a densidade nas Classes I e II foi uma das maiores, parcela número seis.

\section{Discussão}

A regeneração da área estudada, após distúrbio há mais ou menos 50 anos atrás, deveuse à existência de fontes próximas de propágulos e ao papel da fauna como dispersora.
Comparando-se com a lista de espécies obtidas para duas áreas próximas à estudada neste trabalho, situadas na região da Serra da Juréia, dentro da Estação Ecológica de JuréiaItatins, obteve-se 58,7\% de espécies em comum com a floresta de encosta (Mantovani 1993) e 42,2\% com a de planície (Melo et al. 1998). A porcentagem de espécies em comum com estes estudos fornece evidências da importância do entorno e de áreas mais preservadas na manutenção do fluxo de espécies para a regeneração

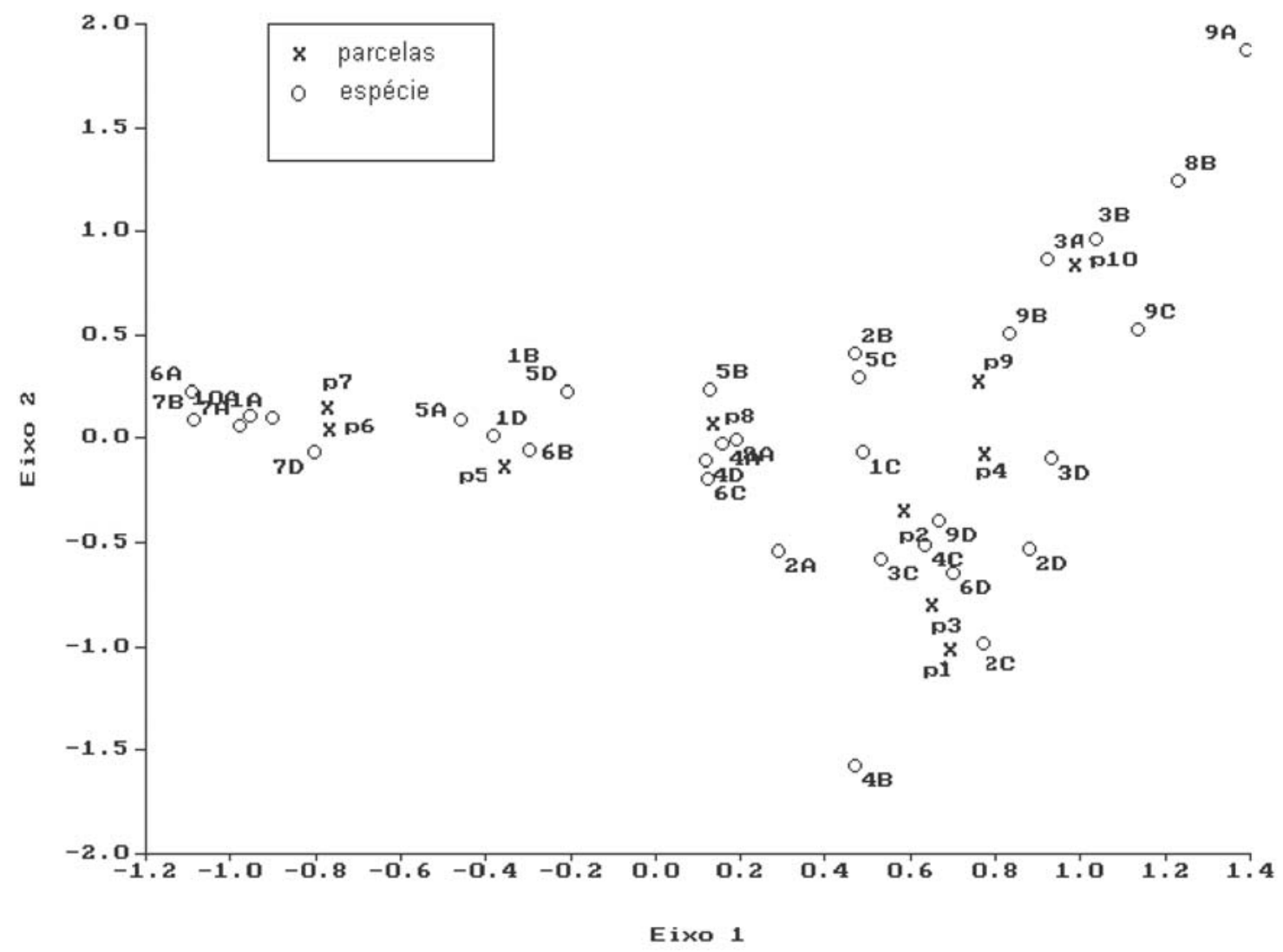

Figura 4. Ordenação das parcelas, através da Análise de Correspondência (CA), pela abundância das dez espécies com maiores números de indivíduos do componente arbustivo-arbóreo da Floresta Atlântica de encosta, no Morro do Fernando (EEJI, Peruibe, SP). As parcelas estão indicadas pela letra p e as espécies, nas Classes I, II, III e IV, pelos códigos correspondentes apresentados na tabela 7. 

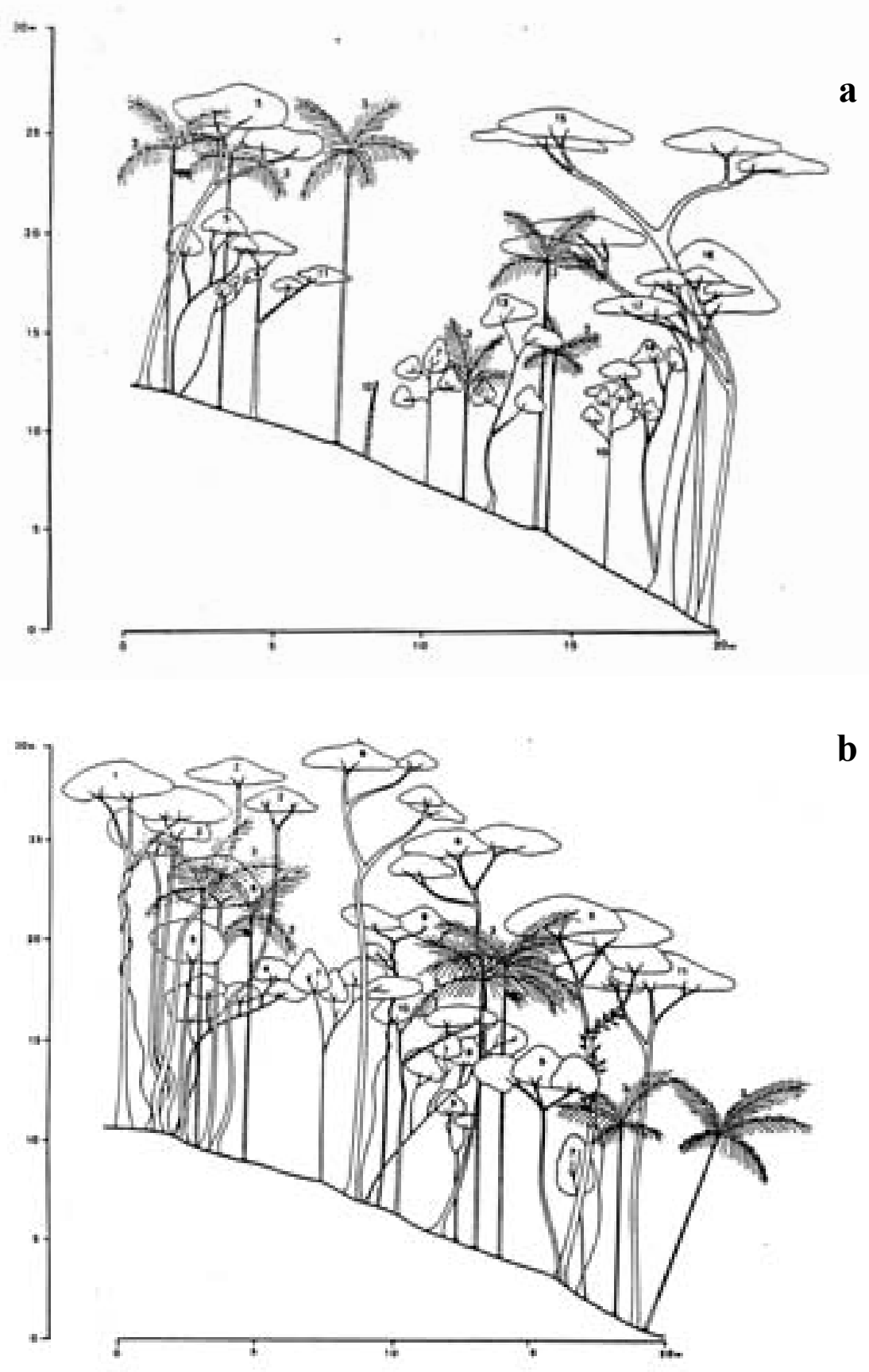

b

Figura 5. Diagramas de perfil da vegetação arbustivo-arbórea confeccionados na parcela oito (a) e seis (b) instaladas em trecho de Floresta Atlântica de encosta, no Morro do Fernando (EEJI, Peruíbe, SP). 1. Ficus pulchella, 2. Campomanesia guaviroba, 3. Euterpe edulis, 4. Eugenia bocainensis, 5. Tabebuia obtusifolia, 6. Pera glabrata, 7. Chrysophyllum flexuosum, 8. Marlierea reitzii, 9. Ilex theezans, 10. Eriotheca pentaphylla, 11. Ecclinusa ramiflora, 12. Trichipteris corcovadensis, 13. Guapira opposita, 14. Heisteria silvianii, 15. Balizia pedicellaris, 16. Chrysophyllum inornatum, 17. Cupania oblongifolia. 
de áreas próximas, assim como, dos altos níveis de diversidade em florestas tropicais (Guariguata et al. 1997).

A obtenção de maior proporção de espécies exclusivas à Classe IV indica tendência de substituição, ou baixa regeneração local, de espécies demandantes de mais luz, como Miconia pyrifolia, Hyeronima alchorneoides e Pourouma guianensis, assim como aquelas que foram mais abundantes na Classe I, como Eupatorium sp. e Myrsine sp., representam o ingresso de colonizadoras que podem se estabelecer, porém o recrutamento é baixo devido às condições locais. Por outro lado, espécies, como Euterpe edulis, Guapira opposita, Eriotheca pentaphylla, Tabebuia obtusifolia, representadas em todas as classes de tamanho e notadamente abundantes na fase de plântula durante o período de estudo, indicam regeneração local.

São espécies secundárias tardias que têm sido freqüentemente amostradas ao longo da encosta Atlântica. G. opposita e E. edulis estão entre as dez de maior ocorrência em trechos de Floresta Pluvial Atlântica, predominando na região sul e sudeste, e E. pentaphylla e $T$. obtusifolia, com distribuição mais restrita à região sudeste (Siqueira 1994).

$\mathrm{Na}$ floresta estudada os processos envolvidos na sua regeneração natural, ou dinâmica, podem se aproximar mais da floresta primária quanto à composição das guildas de regeneração. A maior proporção de espécies secundárias tardias-climácicas, em todas as classes de tamanho, demonstra que as condições ambientais têm favorecido a regeneração deste grupo, em detrimento das pioneiras e secundárias iniciais, que demandam maior luminosidade.

Isto sugere que a estrutura atual poderá manter-se, caso não se alterem os níveis atuais de distúrbios naturais (Denslow 1980; Whitmore 1989). Com o avanço da sucessão, a ocorrência de sítios favoráveis à regeneração das espécies demandantes de luz intensa torna-se cada vez menos freqüente. Em florestas tropicais maduras, a baixa proporção de espécies pioneiras em relação às demais é uma de suas características, já que são dependentes de alta luminosidade para germinação e estabelecimento (Denslow 1980; Martínez-Ramos 1985).

As parcelas cinco, seis e sete, consideradas como as de maior heterogeneidade florística e densidade de indivíduos nas Classes I e II do presente estudo, podem ser caracterizadas como trechos com estrutura mais aberta e dinâmica dentro da área estudada. Isto justifica a presença de Eupatorium sp. (Compositae), espécie pioneira típica de áreas mais abertas, que ocorreu somente como plântulas agrupadas nestas parcelas.

Em áreas de clareiras, onde ocorre maior amplitude de intensidade luminosa em relação às áreas sob dossel, um número maior de indivíduos germinam, aumentando a densidade nestas áreas (Denslow 1980; Cersósimo 1993), porém maior riqueza e diversidade foram verificadas em ambientes de sombra da Floresta Mesófila Semidecídua, por Cersósimo (1993) e da Floreta Alta Perenifólia, por Martínez-Ramos (1991). Estes autores chamam a atenção para a variação micro ambiental nestes ambientes, onde plantas de sub-bosque podem interferir, mais diretamente, no estabelecimento e sobrevivência de plântulas de espécies persistentes.

As espécies Euterpe edulis, Balizia pedicellaris e Eriotheca pentaphylla apresentaram maiores densidades nas parcelas onde ocorreu também o maior número de adultos. No caso das duas primeiras, a agregação pode ter sido favorecida também pela estrutura mais aberta do trecho em que ocorreram, parcelas cinco, seis e sete, enquanto que para $E$. pentaphylla a proximidade da matriz pode ter sido determinada pela síndrome de dispersão autocórica. A distribuição de Tabebuia obtusifolia, aleatória na Classe I e agregada nas demais classes, reflete a ampla dispersão das suas sementes, característica da síndrome anemocórica, e a alta capacidade de germinação, com plântulas distribuídas em quase todas 
as parcelas, enquanto que a agregação dos indivíduos maiores pode estar refletindo condições ambientais que prevaleceram no passado, como grandes clareiras, que não limitaram o crescimento de indivíduos próximos, demonstrando o seu caráter heliofílico.

No presente estudo, as variações em pequena escala se refletem na fisionomia da floresta estudada, embora a ausência de dossel contínuo seja uma característica que distingue a Floresta Pluvial Tropical sobre encostas íngremes, daquelas crescendo sobre uma superfície horizontal (Richards 1996), porque permite a entrada de mais luz entre as árvores. Na área de estudo, a irregularidade observada pode também estar associada aos afloramentos rochosos, impedindo a ocorrência de indivíduos de grande porte em determinados locais.

Algumas espécies, apesar de serem abundantes em classes de tamanho maiores, não foram amostradas como plântulas, o que pode ser atribuído à heterogeneidade na dispersão, no estabelecimento e na sobrevivência, ao período abrangido, ao desenho amostral e ao critério de inclusão estabelecidos para este estudo. Garcinia gardneriana e Andira anthelmia não foram amostradas como plântulas, mas foram observadas em locais próximos às parcelas. No primeiro caso, tratava-se de indivíduo jovem com $19 \mathrm{~cm}$ de altura e, no segundo, de plântula que trazia a semente ainda unida e com as primeiras folhas, mas com altura de $17 \mathrm{~cm}$.

Deve-se considerar, ainda, que a similaridade entre a Classe I, do presente estudo, e as demais poderia ter sido maior, caso tivesse sido considerado o tempo suficiente para abranger os ciclos de reprodução supra-anuais que são freqüentes em muitas espécies de floresta tropical, principalmente as de dossel e emergentes (Martínez-Ramos 1985; Lieberman 1996).

Além do mais, por estar representando a fase de maior dinâmica, o grau de similaridade pode flutuar de acordo com a composição florística dos propágulos de origem externa e daqueles produzidos localmente, durante o período de estudo.

\section{Agradecimentos}

Ao Instituto de Botânica de São Paulo, em especial às PqCs Drs. Lúcia Rossi, Inês Cordeiro e Maria Candida H. Mamede, responsáveis pelo Projeto "Flora fanerogâmica da Serra da Juréia, SP, Brasil", pelo apoio na realização deste estudo; ao Instituto Florestal de São Paulo pela autorização de coleta na EEJI e aos especialistas que auxiliaram na identificação do material botânico: E.A. Anunciação (Rubiaceae); S.A. Nicolau (Lauraceae); H.L. Kawasaki (Myrtaceae) e S.A.C. Chiea (Melastomataceae).

\section{Referências bibliográficas}

Ab'Saber, A.N. 1985. O Ribeira de Iguape: Uma setorização endereçada ao planejamento regional. Boletim Técnico da SUDELPA 1: 1-35.

Budowiski, G. 1970. The distinction between old secondary and climax species in tropical central american lowland forests. Tropical Ecology 11(1): 44-48.

Cersósimo, L. F. 1993. Variações espaciais e temporais no estabelecimento de plântulas em floresta secundária em São Paulo, SP. Dissertação de Mestrado, Universidade de São Paulo. São Paulo.

Córdova-Casillas, B. 1985. Demografia de arboles tropicales. Pp. 191-239. In: A. Gómez-Pompa \& R.S. Del Amo (eds.) Investigaciones sobre la regeneración de selvas alta en Vera Cruz, Mexico. II INEREB, Xalapa. Mexico.

Cronquist, A. 1988. The evolution and classification of flowering plants. $2^{\text {nd }} \mathrm{ed}$. New York Botanical Garden, Bronx.

Delamônica, P. 1997. Estrutura e floristica de floresta atlântica secundária - Reserva Biológica Estadual da Praia do Sul, Ilha Grande, R.J. Dissertação de Mestrado, Universidade de São Paulo. São Paulo.

Denslow, J.S. 1980. Patterns of plant species diversity during succession under different disturbance regimes. Oecologia 46: 18-21.

Denslow, J.S. 1987. Tropical rainforest gaps and tree species diversity. Annual Review of Ecology and 
Systematics. 18: 432-451.

Greig-Smith, P. 1983. Quantitative plant ecology. Blackwell Scientific publications. London.

Guariguata, M.R., Chazdon, R.L., Denslow,J.S., Dupuy, J.M. \& Anderson, L. 1997. Structure and floristic of secondary and old-growth stands in lowland Costa Rica. Plant Ecology 132: 107-120.

Klein, R.M. 1980. Ecologia da flora e vegetação do vale do Itajaí (continuação). Sellowia 32: 165-373.

Knobel, M.G. 1995. Aspectos da regeneração natural do componente arbóreo-arbustivo, de trecho de floresta da Reserva Biológica do Instituto de Botânica em São Paulo, SP. Dissertação de Mestrado, Universidade de São Paulo. São Paulo.

Koeppen, W. 1948. Climatologia: com un estudio de los climas de la tierra. Fundo de Cultura Economica. Mexico.

Krebs, C.J. 1989. Ecological metodology. Harper \& Row. New York.

Leitão-Filho, H.F. (coord) 1993. Ecologia da Mata Atlântica em Cubatão. UNESP, São Paulo/ UNICAMP, Campinas.

Lepsch, I.F., Sakai, E., Prado, H. \& Rizzo L.T.B. 1988. Levantamento de reconhecimento com detalhes dos solos da região do Rio Ribeira de Iguape no Estado de São Paulo (Informe preliminar). Coordenadoria de Pesquisa Agropecuária Instituto Agronômico, Campinas. Escala 1:250.000 (IBGE).

Lieberman, D. 1996. Demography of tropical tree seedlings: A review. Pp.131-138. In: M.D. Swaine (ed.) The ecology of tropical forest tree seedlings. UNESCO and Parthenon Publishing group. Paris.

Magurran, A.E. 1988. Ecological diversity and its mesurement. Chapman \& Hall. London.

Mantovani, W. 1993. Estrutura e dinâmica da Floresta Atlântica na Juréia, Iguape - SP. Tese de Livre Docência, Universidade de São Paulo. São Paulo.

Mantovani, W.; Rodrigues, R.R.; Rossi, L.; Romaniuc Neto, S.; Catharino, E.L.M. \& Cordeiro, I. 1990. A vegetação na Serra do Mar em Salesópolis, SP. Pp. 348-384. In: Anais do Simpósio de Ecossistemas da Costa Sul e Sudeste Brasileira - Estrutura, função e manejo 2. Águas de Lindóia, SP. Academia de Ciências do Estado de São Paulo.V. 1.

Martínez-Ramos, M. 1985. Claros, ciclos vitales de los arboles tropicales y regeneración natural de las selvas altas perennifolias. Pp.191-239. In: A. GómezPompa \& R.S. Del Amo (eds.) Investigaciones sobre la regeneración de las selvas alta en Vera Cruz, Mexico. II INIREB, Xalapa. Mexico.

Martínez-Ramos, M. 1991. Patrones, processos e mecanismos en la comunidad de plantulas de una selva humeda neotropical. Tese de Doutorado, Universidad Nacional de Mexico.

Melo, M.M.R.F. \& Mantovani, W. 1994. Composição florística e estrutura de trecho de Mata Atlântica de encosta, na Ilha do Cardoso (Cananéia, SP, Brasil). Boletim do Instituto de Botânica 9: 107-158.

Melo, M.M.R.F., Oliveira, R.J., Rossi, L, Mamede, M.C.H. \& Cordeiro, I. 1998. Fitossociologia de trecho de mata atlântica na planície do Rio Verde, Estação Ecológica de Juréia-Itatins, SP, Brasil. Pp. 4956. In: Anais do IV Simpósio de

ecossistemas brasileiro, Águas de Lindóia. São Paulo. V 2.

Mueller-Dombois, D. \& Ellenberg, H. 1974. Aims and methods of vegetation ecology. John Wiley. New York.

Nascimento, C.M. \& Pereira, M.A.M.G. 1988. Atlas climatológico do Estado de São Paulo (19771986). Fundação Cargill. Campinas, SP.

Reitz, P.R. (ed.) 1965/1990. Flora Ilustrada Catarinense. Itajaí, SC.

Richards, P.W. 1996. The tropical rain forest: an ecological study. Cambridge University Press. New York.

Rossi, L. 1994. A flora arbóreo-arbustiva da mata da reserva da cidade universitária "Armando de Salles Oliveira” (São Paulo, Brasil). Boletim do Instituto de Botânica 9: 1-105.

Shepherd, G.J. 1996. Fitopac 1: Manual do usuário. Departamento de Botânica, Universidade Estadual de Campinas.

Silva, A.F.S \& Leitão-Filho, H.F. 1982. Composição florística e estrutura de um trecho de mata atlântica de encosta no município de Ubatuba (São Paulo, Brasil). Revista Brasileira de Botânica 5: 43-52.

Siqueira, M.F. 1994. Análise florística e ordenação de espécies arbóreas da Mata Atlântica através de dados binários. Dissertação de Mestrado, Universidade Estadual de Campinas. Campinas.

Swaine, M.D. 1990. Population dynamics of tree species in tropical forests. Pp.101-109. In: LB. HolmNielsen, I.C. Nielsen \& H. Balslev (eds.)Tropical Forests. Academic Press Limited. London.

Tabarelli, M. 1994. Clareiras naturais e a dinâmica sucessional de um trecho de floresta na Serra da Cantareira. Dissertação de Mestrado, Universidade de São Paulo. São Paulo.

Tabarelli, M., Villani, J.P., \& Mantovani, W. 1993. Aspectos da sucessão secundária em floresta atlântica na Parque Estadual da Serra do Mar, SP. Revista do Instituto Florestal 5(1): 99-112.

van der Pijl, P. 1982. Principles of dispersal in higher 
plants. Springer-Verlag. Berlim.

Veloso, H.P., Rangel Filho, A.L.R., Lima, J.C.A. 1991. Classificação da vegetação brasileira adaptada a um sistema universal. Rio de Janeiro: IBGE. Rio de Janeiro.

Whitmore, T.C. 1989. Canopy gaps and the two major groups of forest trees. Ecology 70(3): 536-538.

Whitmore, T.C. 1996. A review of some aspects of tropical rain forest seedling ecology with suggestions for further inquiry. Pp. 3-39. In: M.D. Swaine (ed.) The ecology of tropical forest tree seedlings. UNESCO and Parthenon Publishing group. Paris. 


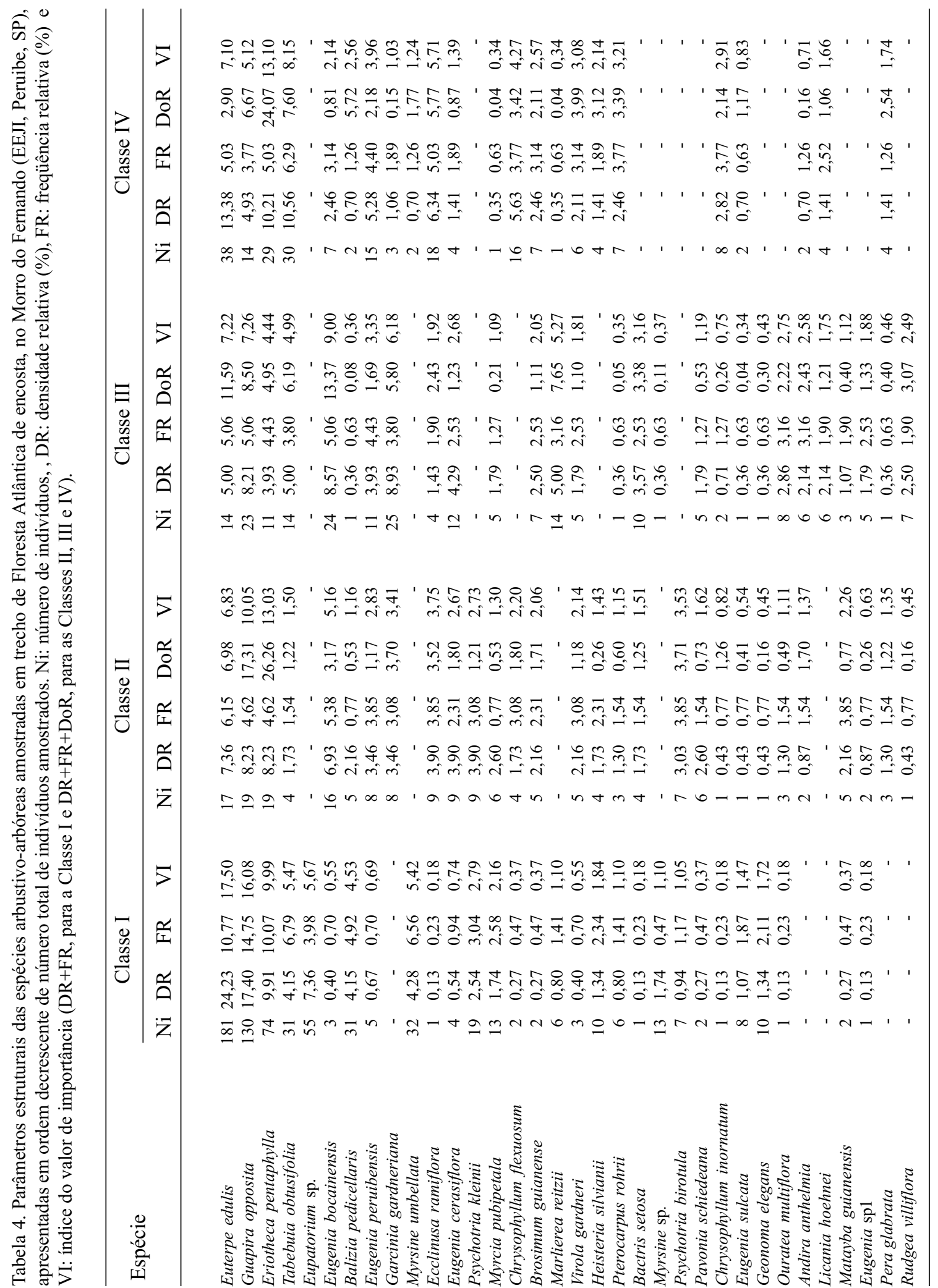




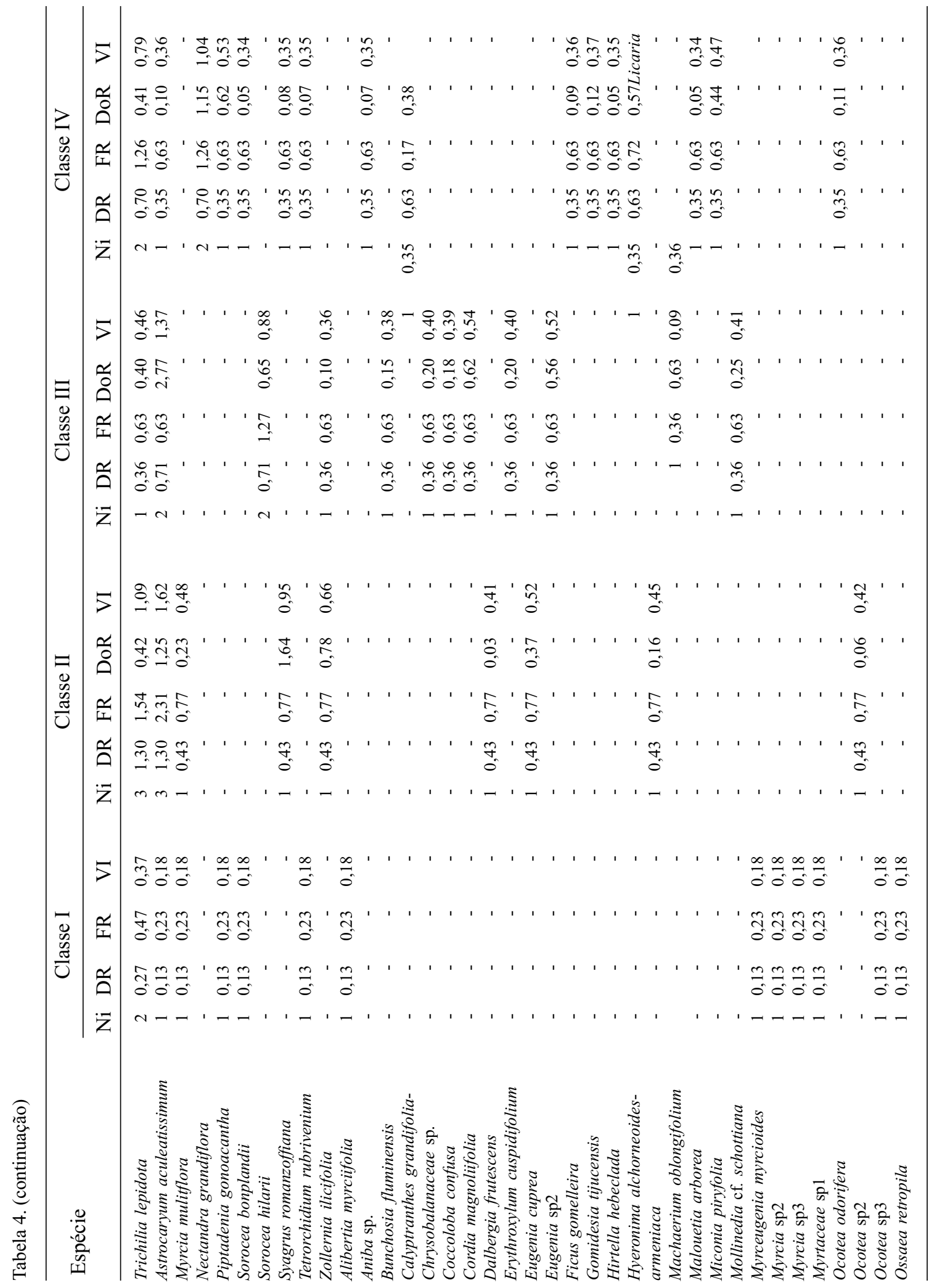




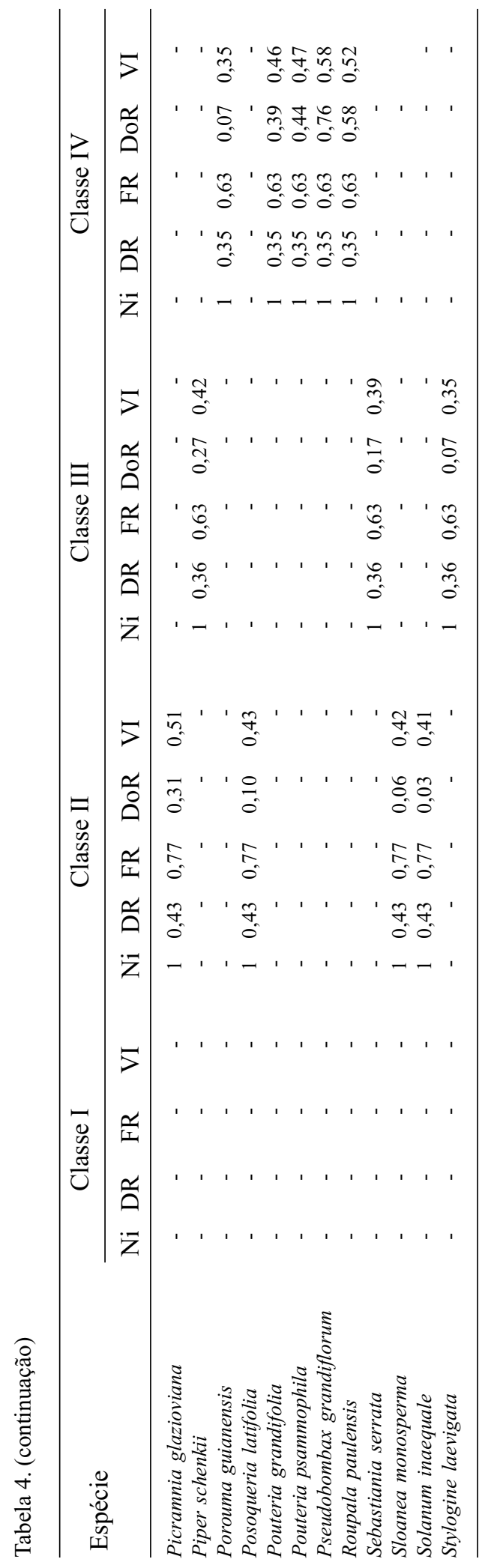


Tabela 2. Lista das espécies arbustivo-arbóreas amostradas em diferentes classes de tamanho (I, II, III, e IV), no período de julho de 1995 a janeiro de 1997, em Floresta Atlântica de encosta, no Morro do Fernando (EEJI, Peruíbe, SP), classificadas quanto à categoria sucessional (SB: sub-bosque, PI: pioneira, SI: secundária inicial, ST: secundária tardiaclimácica) e quanto à síndrome de dispersão dos propágulos (ANE: anemocórica, AUT: autocórica, ZOO: zoocórica).

\begin{tabular}{|c|c|c|c|c|}
\hline Família & Espécie & $\begin{array}{c}\text { Classes de } \\
\text { tamanho }\end{array}$ & $\begin{array}{c}\text { Categoria } \\
\text { sucessional }\end{array}$ & $\begin{array}{l}\text { Síndrome } \\
\text { dispersã }\end{array}$ \\
\hline \multicolumn{5}{|l|}{ PYTERIDOPHYTA } \\
\hline Cyatheaceae & Trichipteris corcovadensis (Raddi) Copel. & IV & SB & ANE \\
\hline \multicolumn{5}{|l|}{ ANGIOSPERMAE } \\
\hline Annonaceae & Xylopia langsdorffiana A. St.- Hil & I,III,IV & SB & $\mathrm{ZOO}$ \\
\hline \multirow[t]{2}{*}{ Apocynaceae } & Aspidosperma olivaceum Muell. Arg. & I,IV & ST & ANE \\
\hline & Malouetia arborea (Vell.) Miers & IV & $\mathrm{ST}$ & AUT \\
\hline Aquifoliaceae & Ilex theezans Mart. & IV & $\mathrm{ST}$ & $\mathrm{ZOO}$ \\
\hline \multirow[t]{5}{*}{ Arecaceae } & Astrocaryum aculeatissimum (Schott) Burret & I,II,III,IV & SI & $\mathrm{ZOO}$ \\
\hline & Bactris setosa Mart. & I,II,III & PI & $\mathrm{ZOO}$ \\
\hline & Euterpe edulis Mart. & I,II,III,IV & ST & $\mathrm{ZOO}$ \\
\hline & Geonoma elegans Mart. & I,II,III & SB & $\mathrm{ZOO}$ \\
\hline & Syagrus romanzoffiana (Cham.) Glassman & II,IV & SI & $\mathrm{ZOO}$ \\
\hline Asteraceae & Eupatorium sp. & I & PI & ANE \\
\hline Bignoniaceae & Tabebuia obtusifolia (Cham.) Bureau & I,II,III,IV & ST & ANE \\
\hline \multirow[t]{2}{*}{ Bombacaceae } & Eriotheca pentaphylla (Vell.) A. Robyns & I,II,III,IV & ST & AUT \\
\hline & Pseudobombax grandiflorum (Cav.) A. Robyns & IV & SI & ANE \\
\hline Boraginaceae & Cordia magnoliifolia Cham. & III & SI & $\mathrm{ZOO}$ \\
\hline Burseraceae & Protium widgrenii Engl. & $\mathrm{I}, \mathrm{IV}$ & ST & $\mathrm{ZOO}$ \\
\hline Caesalpiniaceae & Zollernia ilicifolia (Brongn.) Vogel & II,III & ST & $\mathrm{ZOO}$ \\
\hline Cecropiaceae & Pourouma guianensis Aubl. & IV & SI & $\mathrm{ZOO}$ \\
\hline \multirow[t]{2}{*}{ Celastraceae } & Maytenus robusta Reissek & II,III & SI & $\mathrm{ZOO}$ \\
\hline & Maytenus cf. schumanniana Loes. & I & SB & $\mathrm{ZOO}$ \\
\hline \multirow[t]{4}{*}{ Chrysobalanaceae } & Hirtella hebeclada Moric. ex DC. & IV & SB & $\mathrm{ZOO}$ \\
\hline & Licania hoehnei Pilger & III,IV & $\mathrm{ST}$ & $\mathrm{ZOO}$ \\
\hline & Parinari excelsa Sabine & III,IV & ST & $\mathrm{ZOO}$ \\
\hline & não determinada & III & - & $\mathrm{ZOO}$ \\
\hline \multirow[t]{2}{*}{ Clusiaceae } & Callophyllum brasiliense Cambess. & II,IV & $\mathrm{ST}$ & $\mathrm{ZOO}$ \\
\hline & Garcinia gardneriana (Planch. \& Triana) Zappi & II,III,IV & SB & $\mathrm{ZOO}$ \\
\hline Elaeocarpaceae & Sloanea monosperma Vell. & II & ST & $\mathrm{ZOO}$ \\
\hline Erythroxylaceae & Erythroxylum cuspidifolium Mart. & III & SB & $\mathrm{ZOO}$ \\
\hline \multirow[t]{4}{*}{ Euphorbiaceae } & Hyeronima alchorneoides Allemão & IV & $\mathrm{ST}$ & $\mathrm{ZOO}$ \\
\hline & Pera glabrata (Schott) Baill. & II,III,IV & SI & $\mathrm{ZOO}$ \\
\hline & Sebastiania serrata Muell. Arg. & III & SI & AUT \\
\hline & Tetrorchidium rubrivenium Poepp. & $\mathrm{I}, \mathrm{IV}$ & PI & AUT \\
\hline \multirow[t]{5}{*}{ Fabaceae } & Andira anthelmia (Vell.) Macbride & II,III,IV & ST & $\mathrm{ZOO}$ \\
\hline & Dalbergia frutescens (Vell.) Britton & II & SI & ANE \\
\hline & Machaerium nyctitans (Vell.) Harms. & I & ST & ANE \\
\hline & Machaerium oblongifolium Vogel & III & SB & ANE \\
\hline & Pterocarpus rohrii Vahl & I,II,III,IV & ST & ANE \\
\hline \multirow[t]{2}{*}{ Hippocrateaceae } & Cheiloclinium cognatum (Miers) A.C. Sm. & $\mathrm{I}, \mathrm{II}$ & SB & $\mathrm{ZOO}$ \\
\hline & Salacia grandiflora (Mart.) G. Don & III & SB & $\mathrm{ZOO}$ \\
\hline Lacistemaceae & Lacistema lucidum Schnizl. & I,II,III & ST & $\mathrm{ZOO}$ \\
\hline \multirow[t]{3}{*}{ Lauraceae } & Aniba sp. & IV & ST & $\mathrm{ZOO}$ \\
\hline & Licaria armeniaca (Nees) Koesterm. & II & ST & $\mathrm{ZOO}$ \\
\hline & Nectandra grandiflora Nees \& Mart. ex Nees & IV & ST & $\mathrm{ZOO}$ \\
\hline
\end{tabular}


Tabela 2. (continuação)

\begin{tabular}{|c|c|c|c|c|}
\hline Família & Espécie & $\begin{array}{c}\text { Classes de } \\
\text { tamanho }\end{array}$ & $\begin{array}{c}\text { Categoria } \\
\text { sucessional }\end{array}$ & $\begin{array}{l}\text { Síndrome de } \\
\text { dispersão }\end{array}$ \\
\hline & Ocotea odorifera (Vell.) Rohwer & IV & ST & $\mathrm{ZOO}$ \\
\hline & Ocotea $\mathrm{sp} 1$ & II,IV & - & $\mathrm{ZOO}$ \\
\hline & Ocotea $\mathrm{sp} 2$ & II & - & $\mathrm{ZOO}$ \\
\hline & Ocotea sp3 & I & - & $\mathrm{ZOO}$ \\
\hline Malpighiaceae & Bunchosia fluminensis Griseb. & III & SB & $\mathrm{ZOO}$ \\
\hline Malvaceae & Pavonia schiedeana Steud. & I,II,III & SB & AUT \\
\hline \multirow[t]{2}{*}{ Melastomataceae } & Miconia piryfolia Naudin & IV & SI & $\mathrm{ZOO}$ \\
\hline & Ossaea retropila Triana & I & SB & $\mathrm{ZOO}$ \\
\hline Meliaceae & Trichilia lepidota Mart. & I,II,III,IV & SI & $\mathrm{ZOO}$ \\
\hline \multirow[t]{3}{*}{ Mimosaceae } & Balizia pedicellaris (DC.) Barneby \& J.W. Grimes & es I,II,III,IV & $\mathrm{ST}$ & ANE \\
\hline & Inga capitata Desv. & I,II,III & SB & $\mathrm{ZOO}$ \\
\hline & Piptadenia gonoacantha (Mart.) J.F. Macbride & $\mathrm{I}, \mathrm{IV}$ & SI & ANE \\
\hline Monimiaceae & Mollinedia cf. schottiana (Spreng.) Perkins & III & SB & $\mathrm{ZOO}$ \\
\hline \multirow[t]{5}{*}{ Moraceae } & Brosimum guianense (Aubl.) Huber & I,II,III,IV & ST & $\mathrm{ZOO}$ \\
\hline & Ficus gomelleira Kunth \& Bouché & IV & ST & $\mathrm{ZOO}$ \\
\hline & Ficus pulchella Schott & IV & $\mathrm{ST}$ & $\mathrm{ZOO}$ \\
\hline & $\begin{array}{l}\text { Sorocea bonplandii (Baill.) W.C. Burger, } \\
\text { Lanj.\&Wess. Boer }\end{array}$ & $\mathrm{I}, \mathrm{IV}$ & SB & $\mathrm{ZOO}$ \\
\hline & Sorocea hilarii Gaudich. & III & SB & $\mathrm{ZOO}$ \\
\hline Myristicaceae & Virola gardneri (A. DC.) Warb. & I,II,III,IV & $\mathrm{ST}$ & $\mathrm{ZOO}$ \\
\hline \multirow[t]{3}{*}{ Myrsinaceae } & Myrsine umbellata Mart. & $\mathrm{I}, \mathrm{IV}$ & SI & $\mathrm{ZOO}$ \\
\hline & Myrsine sp. & I,III & SI & $\mathrm{ZOO}$ \\
\hline & Stylogine laevigata (Mart.) Mez & III & SB & $\mathrm{ZOO}$ \\
\hline \multirow[t]{25}{*}{ Myrtaceae } & Calyptranthes grandifolia $\mathrm{O}$. Berg & IV & SB & $\mathrm{ZOO}$ \\
\hline & Calyptranthes lucida Mart. ex DC. & I,II,III & SB & $\mathrm{ZOO}$ \\
\hline & Campomanesia guaviroba (DC.) Kiaersk. & I,IV & SI & $\mathrm{ZOO}$ \\
\hline & Eugenia bocainensis Mattos & I,II,III,IV & SB & $\mathrm{ZOO}$ \\
\hline & Eugenia cerasiflora Miq. & I,II,III,IV & $\mathrm{ST}$ & $\mathrm{ZOO}$ \\
\hline & Eugenia cuprea (O. Berg) Nied. & II & SB & $\mathrm{ZOO}$ \\
\hline & Eugenia multicostata Legrand & IV & SB & $\mathrm{ZOO}$ \\
\hline & Eugenia oblongata $\mathrm{O}$. Berg & II,III,IV & SB & $\mathrm{ZOO}$ \\
\hline & Eugenia peruibensis Mattos & I,II,III,IV & SB & $\mathrm{ZOO}$ \\
\hline & Eugenia pruinosa Legrand & IV & $\mathrm{ST}$ & $\mathrm{ZOO}$ \\
\hline & Eugenia stictosepala Kiaersk. & $\mathrm{I}, \mathrm{IV}$ & $\mathrm{ST}$ & $\mathrm{ZOO}$ \\
\hline & Eugenia sulcata Spring ex Mart. & I,II,III,IV & SI & $\mathrm{ZOO}$ \\
\hline & Eugenia umbelliflora O. Berg & I & SB & $\mathrm{ZOO}$ \\
\hline & Eugenia $\mathrm{sp} 1$ & I,II,III & SB & $\mathrm{ZOO}$ \\
\hline & Eugenia $\mathrm{sp} 2$ & III & SB & $\mathrm{ZOO}$ \\
\hline & Gomidesia schaueriana O. Berg & I,II,III & SB & $\mathrm{ZOO}$ \\
\hline & Gomidesia tijucensis (Kiaersk.) Legrand & IV & SB & $\mathrm{ZOO}$ \\
\hline & Marliera reitzii Legrand & I,III,IV & SB & $\mathrm{ZOO}$ \\
\hline & Myrceugenia myrcioides (Cambess.) O. Berg & I & SB & $\mathrm{ZOO}$ \\
\hline & Myrcia heringii Legrand & $\mathrm{I}, \mathrm{II}$ & SB & $\mathrm{ZOO}$ \\
\hline & Myrcia multiflora (Lam.) DC. & $\mathrm{I}, \mathrm{II}$ & SB & $\mathrm{ZOO}$ \\
\hline & Myrcia pubipetala Miq. & I,II,III,IV & SB & $\mathrm{ZOO}$ \\
\hline & Myrcia sp1 & $\mathrm{I}, \mathrm{II}, \mathrm{III}$ & - & $\mathrm{ZOO}$ \\
\hline & Myrcia $\mathrm{sp} 2$ & I & - & $\mathrm{ZOO}$ \\
\hline & Myrcia $\mathrm{sp} 3$ & I & - & $\mathrm{ZOO}$ \\
\hline
\end{tabular}


Tabela 2. (continuação)

\begin{tabular}{|c|c|c|c|c|}
\hline Família & Espécie & $\begin{array}{r}\text { Classes de } \\
\text { tamanho }\end{array}$ & $\begin{array}{l}\text { Categoria } \\
\text { sucessional }\end{array}$ & $\begin{array}{l}\text { Síndrome de } \\
\text { dispersão }\end{array}$ \\
\hline \multicolumn{5}{|l|}{ PYTERIDOPHYTA } \\
\hline Cyatheaceae & Trichipteris corcovadensis (Raddi) Copel. & IV & SB & ANE \\
\hline \multicolumn{5}{|l|}{ ANGIOSPERMAE } \\
\hline Annonaceae & Xylopia langsdorffiana A. St.- Hil & I,III,IV & SB & $\mathrm{ZOO}$ \\
\hline \multirow[t]{2}{*}{ Apocynaceae } & Aspidosperma olivaceum Muell. Arg. & $\mathrm{I}, \mathrm{IV}$ & ST & ANE \\
\hline & Malouetia arborea (Vell.) Miers & IV & ST & AUT \\
\hline Aquifoliaceae & Ilex theezans Mart. & IV & ST & $\mathrm{ZOO}$ \\
\hline \multirow[t]{5}{*}{ Arecaceae } & Astrocaryum aculeatissimum (Schott) Burret & I,II,III,IV & SI & $\mathrm{ZOO}$ \\
\hline & Bactris setosa Mart. & I,II,III & PI & $\mathrm{ZOO}$ \\
\hline & Euterpe edulis Mart. & I,II,III,IV & ST & $\mathrm{ZOO}$ \\
\hline & Geonoma elegans Mart. & I,II,III & SB & $\mathrm{ZOO}$ \\
\hline & Syagrus romanzoffiana (Cham.) Glassman & II,IV & SI & $\mathrm{ZOO}$ \\
\hline Asteraceae & Eupatorium sp. & I & PI & ANE \\
\hline Bignoniaceae & Tabebuia obtusifolia (Cham.) Bureau & I,II,III,IV & ST & ANE \\
\hline \multirow[t]{2}{*}{ Bombacaceae } & Eriotheca pentaphylla (Vell.) A. Robyns & I,II,III,IV & ST & AUT \\
\hline & Pseudobombax grandiflorum (Cav.) A. Robyns & IV & SI & ANE \\
\hline Boraginaceae & Cordia magnoliifolia Cham. & III & SI & $\mathrm{ZOO}$ \\
\hline Burseraceae & Protium widgrenii Engl. & $\mathrm{I}, \mathrm{IV}$ & ST & $\mathrm{ZOO}$ \\
\hline Caesalpiniaceae & Zollernia ilicifolia (Brongn.) Vogel & II,III & ST & $\mathrm{ZOO}$ \\
\hline Cecropiaceae & Pourouma guianensis Aubl. & IV & SI & $\mathrm{ZOO}$ \\
\hline \multirow{2}{*}{ Celastraceae } & Maytenus robusta Reissek & II,III & SI & $\mathrm{ZOO}$ \\
\hline & Maytenus cf. schumanniana Loes. & I & SB & $\mathrm{ZOO}$ \\
\hline \multirow[t]{4}{*}{ Chrysobalanaceae } & Hirtella hebeclada Moric. ex DC. & IV & SB & $\mathrm{ZOO}$ \\
\hline & Licania hoehnei Pilger & III,IV & ST & $\mathrm{ZOO}$ \\
\hline & Parinari excelsa Sabine & III,IV & ST & $\mathrm{ZOO}$ \\
\hline & não determinada & III & - & $\mathrm{ZOO}$ \\
\hline \multirow[t]{2}{*}{ Clusiaceae } & Callophyllum brasiliense Cambess. & II,IV & ST & $\mathrm{ZOO}$ \\
\hline & Garcinia gardneriana (Planch. \& Triana) Zappi & II,III,IV & SB & $\mathrm{ZOO}$ \\
\hline Elaeocarpaceae & Sloanea monosperma Vell. & II & ST & $\mathrm{ZOO}$ \\
\hline Erythroxylaceae & Erythroxylum cuspidifolium Mart. & III & SB & $\mathrm{ZOO}$ \\
\hline \multirow[t]{4}{*}{ Euphorbiaceae } & Hyeronima alchorneoides Allemão & IV & ST & $\mathrm{ZOO}$ \\
\hline & Pera glabrata (Schott) Baill. & II,III,IV & SI & $\mathrm{ZOO}$ \\
\hline & Sebastiania serrata Muell. Arg. & III & SI & AUT \\
\hline & Tetrorchidium rubrivenium Poepp. & $\mathrm{I}, \mathrm{IV}$ & PI & AUT \\
\hline \multirow[t]{5}{*}{ Fabaceae } & Andira anthelmia (Vell.) Macbride & II,III,IV & ST & $\mathrm{ZOO}$ \\
\hline & Dalbergia frutescens (Vell.) Britton & II & SI & ANE \\
\hline & Machaerium nyctitans (Vell.) Harms. & I & ST & ANE \\
\hline & Machaerium oblongifolium Vogel & III & SB & ANE \\
\hline & Pterocarpus rohrii Vahl & I,II,III,IV & ST & ANE \\
\hline \multirow[t]{2}{*}{ Hippocrateaceae } & Cheiloclinium cognatum (Miers) A.C. Sm. & $\mathrm{I}, \mathrm{II}$ & SB & $\mathrm{ZOO}$ \\
\hline & Salacia grandiflora (Mart.) G. Don & III & SB & $\mathrm{ZOO}$ \\
\hline Lacistemaceae & Lacistema lucidum Schnizl. & I,II,III & ST & $\mathrm{ZOO}$ \\
\hline \multirow[t]{5}{*}{ Lauraceae } & Aniba sp. & IV & ST & $\mathrm{ZOO}$ \\
\hline & Licaria armeniaca (Nees) Koesterm. & II & ST & $\mathrm{ZOO}$ \\
\hline & Nectandra grandiflora Nees \& Mart. ex Nees & IV & ST & $\mathrm{ZOO}$ \\
\hline & Ocotea odorifera (Vell.) Rohwer & IV & ST & $\mathrm{ZOO}$ \\
\hline & Ocotea $\mathrm{sp} 1$ & II,IV & - & $\mathrm{ZOO}$ \\
\hline
\end{tabular}

